\title{
Degradabilidade Ruminal In Situ da Matéria Seca e Proteína Bruta de Duas Variedades de Grão de Soja com Diferentes Teores de Inibidor de Tripsina, em Bovinos
}

\author{
Leandro das Dores Ferreira da Silva ${ }^{1}$, Bruno Mazzer de Oliveira Ramos ${ }^{2}$, Edson Luis de \\ Azambuja Ribeiro', Ivone Yurika Mizubuti ${ }^{1}$, Marco Antônio da Rocha ${ }^{1}$, Fábio Lucas Zito de Moraes ${ }^{3}$
}

RESUMO - Foram utilizados quatro bovinos da raça holandesa canulados no rúmen, distribuídos em blocos, ao acaso, alimentados a pasto de coast-cross (Cynodon dactylon). Os animais foram suplementados com ração concentrada contendo grãos de soja moídos colocados no rúmen, às sete e às dezoito horas. Em todos os animais foram incubados sacos de náilon com amostras de cada tratamento: grãos de soja comercial moídos (S), grãos de soja comercial moídos e parcialmente desengordurados (SD), grãos de soja com baixo inibidor de tripsina moídos (SBIT); grãos de soja com baixo inibidor de tripsina moídos e parcialmente desengordurados (SBITD); e farelo de soja (FS). Determinaram-se os desaparecimentos no rúmen da matéria seca (MS), matéria orgânica (MO) e proteína bruta (PB) nos tempos de 6, 24 e 48 horas. As solubilidades da MS, MO e da PB do $\mathrm{S}$ foram superiores às determinadas para o SBIT. A degradabilidade potencial (DP) apresentou valores semelhantes entre os alimentos. A degradabilidade efetiva (DE) da MS e MO dos SBS foi $9 \%$ menor que os valores observados para S e a DE da PB do SBIT foi aproximadamente 6\% menor. Todos os alimentos apresentaram altas velocidades de degradação dos componentes estudados, variando de 5\%/hora para o FS a 15\%/hora para SBITD, enquanto os SBIT apresentaram menor taxa de degradação. Estes valores sugerem que estes alimentos devem ser associados a outros com menores velocidades de fermentação nas rações de ruminantes, para que haja melhor sincronismo entre liberação de amônia, aminoácido, peptídeos e cetoácidos no rúmen, quando for necessário maximizar a produção de proteína microbiana e/ou aumentar a quantidade de proteína bypass.

Palavras-chave: solubilidade, matéria orgânica, degradabilidade potencial, degradabilidade efetiva, taxa de degradação

\section{Dry Matter and Crude Protein in situ Ruminal Degradability of Two Varieties of Ground Soybean with Different Levels of Trypsin Inhibitor in Cattle}

\begin{abstract}
Four ruminally fistulated Holstein, distributed in randomized blocks and fed with coastcross grass, were used. They were supplemented with $2 \mathrm{~kg}$ of concentrate containing ground soybean, put through the rumen fistula daily, at 7 a.m. and $6 \mathrm{p} . \mathrm{m}$. Nylon bags were incubated into the rumen of each animal, and contained samples of each of the following feed: ground soybean (S); low fat ground soybean (LFS); ground low trypsin inhibitor soybean (LTIS); ground low fat and low trypsin inhibitor soybean (LFLTIS); and soybean meal (SM). Dry matter (DM), organic matter (OM) and crude protein $(\mathrm{CP})$ solubility and disappearance into the rumen were determined after 6, 24 and 48 hours of incubation. The DM, OM and CP solubilities of S were higher than low trypsin inhibitor soybean. The DM and OM effective degradability (ED) of LTIS was about $9 \%$ lower than the observed values of S and the ED of the LTIS crude protein was about $6 \%$ lower. All feedstuffs showed high degradation rate for the studied nutritive components, with fermentation rates varying from $5 \%$ for SM to $15 \%$ /hour for LFLTIS. The LTIS showed the lowest nutritive component degradation. The values suggest that these feedstuffs should be associated with others with low degradation velocity for ruminant feed as a way of improving the synchronization between the release of ammonia, aminoacid, peptides and ketoacids into the rumen, when the increase of microbial protein yield and/or increase the amount of bypass protein is necessary.
\end{abstract}

Palavras-chave: solubilidade, matéria orgânica, degradabilidade potencial, degradabilidade efetiva, taxa de degradação

\section{Introdução}

A soja integral e os subprodutos derivados do beneficiamento do grão de soja podem ser considerados os principais fornecedores de proteína nas rações para os animais domésticos. O grão integral contém em média $38 \%$ de proteína bruta, $17,7 \%$ de óleo e energia digestível equivalente a $3962 \mathrm{kcal} / \mathrm{kg}$ de MS, sendo que o farelo de soja contém $45 \%$ de proteína bruta, aproximadamente $1,4 \%$ de óleo e $3448 \mathrm{kcal} / \mathrm{kg}$ de MS de energia digestível. Estas características nutricionais permitem que o mesmo seja usado para reduzir os custos com a alimentação, uma vez que o grão de soja integral pode ser processado na propriedade a preço inferiores ao do farelo de soja.

\footnotetext{
${ }^{1}$ Professor do Departamento de Zootecnia/CCA. Universidade Estadual de Londrina. Campus Universiário. Rodovia Celso Garcia Cid S/N. Londrina, PR. E.mail: leandro@uel.brou Idfs52@hotmail.com

2 Estudante de Mestrado em Ciência Animal/Departamento de Zootecnia/CCA/UEL.

3 Médico Veterinário/CCA/UEL.
} 
O grão de soja in natura e alguns de seus subprodutos possuem fatores antinutricionais que interferem no aproveitamento de suas proteínas pelos animais domésticos. Green \& Lyman (1972), estudando o mecanismo dos inibidores de tripsina que induziam a hipertrofia/hiperplazia, verificaram que a secreção pancreática foi controlada através de retroalimentação negativa e que a secreção enzimática foi inversamente proporcional à quantidade de tripsina presente no intestino. Verificaram, ainda, que o Colicistoquinina (CCK), agente mediador entre a tripsina e o pâncreas, liberado pelas células endócrinas do jejuno, diminuiu o nível de tripsina no intestino.

A tripsina e a quimotripsina são enzimas ricas em cistina, portanto, a hipersecreção dessas enzimas aumenta o requerimento em aminoácidos sulfurosos. Krogdah \& Holm (1979) verificaram que a presença de inibidores destas enzimas elevaram os seus déficits e interferiram no crescimento de ratos.

Há dois tipos de inibidores de proteinases: inibidores de tripsina Knnitz (KIT) e inibidores de tripsina Bowman-Birk (BBIT). Os BBIT consistem de 71 aminoácidos ligados por sete pontes dissulfeto, formando uma molécula compacta e relativamente termo-estável, possuem sítios de ligações independentes para a tripsina e quimotripsina (Weder, 1985). Os KIT possuem 181 resíduos de aminoácidos com duas pontes dissulfetos e especificidade primária à tripsina. Estes inibidores formam complexos estáveis com as enzimas através de seus sítios ativos (Snyder \& Kwon, 1987). Dentro dessas duas classes existem as formas isoinibidoras, sendo conhecidas quatro formas de KIT e múltiplas formas de isoinibidores de BBIT. Entretanto, uma cultitivar de soja foi descrita por possuir no máximo duas formas de KIT, e de 5 a 12 formas de isoinibidores de BBIT (Tan Wilson \& Wilson, 1986).

A Empresa Brasileira de Pesquisa Agropecuária (EMBRAPA) sediada em Londrina, PR, vem desenvolvendo uma variedade de grãos de soja com baixos teores de inibidor de tripsina, sendo, neste caso, dispensável submetê-los ao calor para inativação dos princípios antitripsínico da soja tradicional, principalmente para os animais não ruminantes.

A inativação térmica de inibidores de tripsina e a desnaturação térmica das globulinas da soja aumentam a suscetibilidade às proteólises e melhoram a qualidade da proteína para alimentação humana e animal. Quando há excesso de aquecimento, o valor nutricional reduz, possivelmente, devido às ligações cruzadas das cadeias peptídicas pela acilação dos grupos de aminoácidos livres. Estas ligações cruzadas tornam a lisina indisponível, devido à acilação ou às dificuldades de hidrolisar as pontes peptídicas (Snyder \& Kwon, 1987).

Por outro lado, a intensidade da degradação ruminal da proteína bruta de um alimento, segundo Orskov (1988), é um dos principais indicadores nas avaliações da qualidade da proteína para os animais ruminantes. A quantidade efetivamente digerida no rúmen influi diretamente sobre a disponibilidade de nitrogênio para o crescimento dos microrganismos no rúmen e na quantidade de proteína que chega aos outros compartimentos do trato digestivo para digestão e absorção. No entanto, a degradabilidade efetiva no rúmen depende de características inerentes ao alimento, do nível de ingestão, dos tipos e formas de processamento a que os alimentos foram submetidos e de possíveis limitações nos processos de fermentações no rúmen, principalmente do estado sanitário do animal.

Orskov (1988), estudando o desaparecimento da proteína após incubação de 9 e 24 horas, em bovinos, encontrou valores, respectivamente de 59,0 e $51,3 \%$ para farinha de peixe; de 34,1 e $42,3 \%$ para farinha de carne e ossos e de 49,0 e 89,2\% para farelo de soja, demonstrando que existem grandes diferenças de degradabilidades entre os suplementos protéicos. Outros autores demonstraram que a degradabilidade da farinha de peixe poderia variar em até $53 \%$, devido aos processos sofridos durante sua obtenção.

Por outro lado, Broderick et al. (1991) afirmaram que em situação ótima de nutrição e alimentação dos animais ruminantes, a quantidade de aminoácidos disponíveis para a absorção deve ser igual à necessidade de aminoácidos necessária para atender as exigências de manutenção e produção. No entanto, para se obter elevados níveis de produção e para satisfazer os altos requerimentos de proteína, devese melhorar a eficiência microbiana em síntese protéica associado à adição de fontes protéicas não degradáveis no rúmen. Portanto, são necessários mais estudos sobre a degradabilidade dos componentes nutricionais dos vários produtos e subprodutos produzidos pela agroindústria brasileira, visando sua utilização na alimentação animal.

O objetivo deste trabalho é avaliar a degradabilidade potencial e efetiva de variedades de grãos de soja comercial na forma in natura e desengordurados, de variedades de grãos de soja com

R. Bras. Zootec., v.31, n.3, p.1251-1257, 2002 
baixos teores antitrípticos na forma in natura e desengordurados e do farelo de soja comercial, usando a técnica dos sacos de náilon em novilhos holandeses alimentados a pasto de coast-cross.

\section{Material e Métodos}

O experimento foi realizado nas dependências do Departamento de Zootecnia e na Fazenda Escola do Centro de Ciências Agrárias da Universidade Estadual de Londrina. Foram utilizados quatro bovinos da raça holandesa, com idade média de 3 anos, castrados, pesando em média $500 \mathrm{~kg}$ e canulados no rúmen. Após a recuperação cirúrgica, os animais foram everminados e adaptados por 15 dias e alimentados durante o período experimental com grãos de soja moídos e pasto de coast-cross (Cynodon dactylon). Os grãos de soja moídos foram fornecidos em uma mistura composta com $47,62 \%$ de soja crua triturada, $47,62 \%$ de milho triturado e $4,76 \%$ de sal mineralizado. Foram colocados, diretamente no rúmen, via cânula ruminal, $2 \mathrm{~kg}$ desta mistura em cada animal, diariamente, às 7 e $18 \mathrm{~h}$, durante todo o período experimental.

Os tratamentos usados foram: grãos de soja comercial moídos (S); grãos de soja comercial moídos e parcialmente desengordurados (SD); variedade de grãos de soja com baixo teor de inibidor de tripsina moídos (SBIT); variedade de grãos de soja com baixo teor de inibidor da tripsina moídos e parcialmente desengordurados (SBITD); e farelo de soja comercial (FS). A composição química dos alimentos usados neste trabalho pode ser visualizada na Tabela 1 .

Os alimentos, variedades de grãos de soja com alto e baixo teor de inibidor da tripsina e farelo de soja comercial, foram trituradas em moinho, tipo Willey, dotado de peneira com crivos de $2 \mathrm{~mm}$ de diâmetro. Amostras de $300 \mathrm{~g}$, após trituração dos grãos, foram desengorduradas por 6 (seis) horas, através de lavagem com éter de petróleo (pa). Os teores de matéria seca (MS) dos diferentes alimentos foram determinados conforme metodologias citadas por Silva (1990). Amostras de 6 (seis) gramas de matéria seca, aproximadamente, foram colocadas em sacos de náilon $100 \%$ poliamida, cru pós-fixado, com poros de 50 micrômetros e dimensões de $14,00 \times 7,00 \mathrm{~cm}$ de comprimento e largura, respectivamente.

Foram usados 4 (quatro) tempos de incubação para cada tratamento $(0,6,24$ e 48 horas $)$, de tal forma que em cada animal foram incubados, para cada tempo, os sacos de náilon, contendo amostras dos diferentes alimentos estudados. As incubações foram realizadas, seguindo a inversão do tempo, de tal forma que todos os sacos incubados foram retirados do rúmen no final do período de fermentação. Para a fixação dos sacos de náilon foram usados mosquetões presos a uma corrente com $500 \mathrm{~g}$ de peso e $60 \mathrm{~cm}$ de guia. Para as determinações das solubilidades das diferentes frações nutritivas estudadas foi usado um

Tabela 1 - Teores de matéria seca (MS), matéria orgânica (MO), proteína bruta (PB) dos alimentos estudados e de inibidor de tripsina (IT) nos grãos integrais de soja

Table 1 - Dry matter (DM), organic matter (OM) and crude protein (CP) in the studied feeds, and trypsin inhibitor (TI) level in the soybean

\begin{tabular}{|c|c|c|c|c|}
\hline $\begin{array}{l}\text { Alimento } \\
\text { Feed }\end{array}$ & $\begin{array}{l}\mathrm{MS}(\%) \\
D M(\%)\end{array}$ & $\begin{array}{c}\mathrm{MO}(\% \mathrm{MS}) \\
O M(\%)\end{array}$ & $\begin{array}{c}\mathrm{PB}(\%)(\% \mathrm{MS}) \\
C P(\%)\end{array}$ & $\mathrm{IT}^{1}(\mathrm{mg} / \mathrm{g} \mathrm{MS})$ \\
\hline $\begin{array}{l}\mathrm{S}^{2} \\
S^{2}\end{array}$ & 90,43 & 94,96 & 39,47 & 22,1 \\
\hline $\begin{array}{l}\mathrm{SD}^{3} \\
L F S^{3}\end{array}$ & 91,83 & 94,66 & 48,96 & - \\
\hline $\begin{array}{l}\text { SBIT }^{4} \\
\text { LSTI }^{4}\end{array}$ & 95,82 & 94,72 & 39,84 & 9,6 \\
\hline $\begin{array}{l}\text { SBITD }^{5} \\
\text { LFLTIS }^{5}\end{array}$ & 92,78 & 93,50 & 46,34 & - \\
\hline $\begin{array}{l}\mathrm{FS}^{6} \\
S M^{6}\end{array}$ & 90,16 & 92,61 & 47,47 & - \\
\hline
\end{tabular}

$1_{1}$ Dados obtidos no Laboratório de Nutrição na UEL, Subprojeto "Desenvolvimento de germoplasma de soja com características adequadas para o consumo humano in natura e para a indústria de alimentos" EMBRAPA - Soja.

$2 \mathrm{~S}=$ grãos de soja comercial moídos ( $S=$ ground soybean).

${ }^{3} \mathrm{SD}=$ grãos de soja comercial moídos e desengordurados (LFS = ground low fat soybean).

${ }^{4} \mathrm{SBIT}=$ grãos de soja moídos com baixo teor inibidor de tripsina (LSTI = ground low trypsin inhibitor).

5 SBITD = grãos de soja moídos com baixo teor inibidor de tripsina e desengordurados (LFLTIS = ground low fat and low trypsin inhibitor).

${ }^{6} \mathrm{FS} \quad$ farelo de soja $(S M=$ soybean meal).

R. Bras. Zootec., v.31, n.3, p.1251-1257, 2002 
saco de náilon para cada tratamento por animal, considerado o tempo 0; e para os demais, tempos de 6, 24 e 48 horas foram usados 2, 3 e 4 sacos, respectivamente, por tratamento/animal.

Após a fermentação, os sacos foram retirados do rúmen e lavados, ainda presos à corrente, para retirada dos excessos de material do rúmen presos aos sacos de náilon, depois deixados em repouso em água com gelo por 30 minutos para diminuir a atividade microbiana. Em seguida, foram retirados das correntes e lavados manualmente em água corrente. Após lavados os sacos, os resíduos foram colocados em estufa a $55 \pm 5^{\circ} \mathrm{C}$ com circulação forçada de ar por 72 horas, retirados da estufa e após equilíbrio com a temperatura e umidade do meio ambiente, foram pesados individualmente.

Os sacos correspondentes ao tempo 0 (zero) horas, de cada tratamento e animal, passaram por todos os processos, exceto a incubação intra-ruminal para determinações dos teores solúveis de cada alimento.

Os resíduos nos sacos de náilon foram misturados, homogeneizados e triturados, de tal forma que se obteve uma amostra composta por tempo de incubação por animal. As determinações dos teores de matéria seca, cinzas e de proteína bruta foram realizadas conforme metodologias citadas por Silva (1990).

Para a avaliação da degradabilidade potencial da matéria seca, da matéria orgânica e da proteína bruta foi usado o modelo proposto por Orskov \& McDonald (1979); em que $\mathrm{p}=\mathrm{a}+\mathrm{b}(1-\mathrm{ekt})$, em que: $\mathrm{p}=$ degradabilidade potencial do componente nutritivo em percentagem, $a$ = fração solúvel em percentagem , $\mathrm{b}=$ fração insolúvel, potencialmente degradável, do componente nutritivo, $\mathrm{a}+\mathrm{b}=$ degradabilidade potencial do componente nutritivo, $\mathrm{k}=$ taxa de digestão por ação fermentativa em percentagem por hora e $\mathrm{t}=$ tempo de incubação em horas.

Para estimar a degradabilidade efetiva foi usada a expressão $\mathrm{P}=\mathrm{a}+\mathrm{b}^{*} \mathrm{kd}(\mathrm{kd}+\mathrm{kp})-1$ sendo $: \mathrm{P}=\mathrm{a}$ degradabilidade efetiva em percentagem, $\mathrm{kd}=$ taxa de fermentação em \%/hora, e $\mathrm{kp}=$ ritmo de fluxo das frações nutritivas por hora. Foi usado um kp de $5 \%$ / hora, sugerido pelo AFRC (1993), e "a" e "b" as mesmas constantes da equação anteriormente citada.

Usou-se um delineamento experimental de blocos ao acaso com cinco tratamentos, sendo as variações entre animais controladas pelos blocos. Os dados obtidos foram submetidos a análise de variância (ANOVA), e as diferenças entre médias comparadas pelo Teste de Tukey $(\mathrm{P}<0,050)$.

R. Bras. Zootec., v.31, n.3, p.1251-1257, 2002

\section{Resultados e Discussão}

A degradabilidade da matéria seca (MS), da matéria orgânica $(\mathrm{MO})$ e da proteína bruta $(\mathrm{PB})$ verificada com 6,24 e 48 horas de incubação no rúmen, dos alimentos estudados, pode ser visualizada na Tabela 2.

O farelo de soja apresentou solubilidade de $38,87 \%$ e $36,76 \%$ para matéria seca e matéria orgânica, respectivamente. Estes teores foram menores $(\mathrm{P}<0,05)$ do que os observados para os demais alimentos estudados. As frações solúveis, rapidamente degradáveis, da MS e da MO observadas neste trabalho foram semelhantes enquanto os $56,99 \%$ de proteína solúveis foram superiores aos $25,6 \%$ divulgadas por Silva (1999).

Os grãos de soja comercial com alto teor de inibidor tríptico apresentaram maiores $(\mathrm{P}<0,05)$ solubilidades da MS, MO e da PB do que os grãos de soja com baixos teores de inibidor tríptico. O mesmo foi observado quando estes alimentos foram desengordurados.

Entretanto, neste estudo, foram observadas maiores taxas de solubilidade e desaparecimento de MS, MO e de PB durante as seis primeiras horas de fermentação dos grãos de soja integral com alto ou baixo inibidor tríptico do que quando os mesmos foram desengordurados. Observações semelhantes foram encontradas por Brisola et al. (1998) com grãos de soja integral extrusado e semi-integral extrusado, parcialmente desengordurados. Por outro lado, observa-se que a solubilidade da MO do grão de soja moído, quando desengordurado, foi menor do que aquela observada para o grão de soja moído com baixo inibidor de tripsina.

O desaparecimento da MS do grão de soja moído desengordurado, no tempo 0 (zero), apresentou-se superior ao grão de soja moído e desengordurado com baixo inibidor tríptico. A solubilidade da MS, MO, e $\mathrm{PB}$ do farelo de soja foi inferior aos demais alimentos estudados.

A solubilidade da MS do grão de soja comercial determinada neste trabalho foi superior aquelas observadas por Deschamps (1994), Castillo et al. (1993) e Valadares Filho et al. (1990), respectivamente, 23,14; 26,9; e 47,51\%. Os altos níveis de solubilidades encontradas neste trabalho, possivelmente possam ser atribuídos às perdas de partículas sólidas pelos poros dos sacos de náilon, devido, principalmente, à maior pulverulência das amostras, quando trituradas. 
Tabela 2 - Degradabilidade da matéria seca, da matéria orgânica e da proteína bruta da soja com alto inibidor tríptico (S), da soja com baixo inibidor tríptico (SBIT), da soja com alto inibidor tríptico desengordurado (SD), da soja com baixo inibidor tríptico desengordurado (SBITD) e do farelo de soja (FS)

Table 2 - Dry matter, organic matter and crude protein degradability of ground soybean (S), low fat ground soybean (LFS), ground low trypsin inhibitor soybean (LSTI), ground low fat and low trypsin inhibitor soybean (LFLTIS) and soybean meal (SM)

\begin{tabular}{|c|c|c|c|c|}
\hline \multirow[t]{2}{*}{$\begin{array}{l}\text { Alimentos } \\
\text { Feeds }\end{array}$} & \multicolumn{4}{|c|}{$\begin{array}{l}\text { Tempo (horas) } \\
\text { Time (hours) }\end{array}$} \\
\hline & 0 & 6 & 24 & 48 \\
\hline & \multicolumn{4}{|c|}{$\begin{array}{c}\text { Matéria seca }(\%)^{1} \\
\text { Dry matter }(\%)^{1}\end{array}$} \\
\hline $\begin{array}{l}\mathrm{S}^{2} \\
S^{2}\end{array}$ & $81,21^{\mathrm{a}}$ & $82,55^{\mathrm{a}}$ & $97,46^{\mathrm{a}}$ & $99,83^{\mathrm{a}}$ \\
\hline $\begin{array}{l}\mathrm{SD}^{3} \\
L F S^{3}\end{array}$ & $65,24^{\mathrm{b}}$ & $69,06^{\mathrm{b}}$ & $94,76^{\mathrm{a}}$ & $99,23^{b}$ \\
\hline $\begin{array}{l}\text { SBIT }^{4} \\
\text { LSTI }^{4}\end{array}$ & $54,96^{\mathrm{c}}$ & $63,06^{\mathrm{b}}$ & $91,47^{\mathrm{a}}$ & $99,82^{\mathrm{a}}$ \\
\hline $\begin{array}{l}\text { SBITD }^{5} \\
\text { LFLTIS }\end{array}$ & $52,69^{d}$ & $60,99^{b c}$ & $96,23^{\mathrm{a}}$ & $99,30^{b}$ \\
\hline $\begin{array}{l}\mathrm{FS}^{6} \\
S M^{6}\end{array}$ & $38,87^{\mathrm{e}}$ & $52,94^{\mathrm{c}}$ & $88,06^{\mathrm{a}}$ & $98,65^{\mathrm{c}}$ \\
\hline $\mathrm{CV}$ & \multicolumn{4}{|c|}{$\begin{array}{c}\text { Matéria orgânica }(\%)^{1} \\
\text { Organic matter }(\%)^{1}\end{array}$} \\
\hline $\begin{array}{l}\mathrm{S}^{2} \\
S^{2}\end{array}$ & $80,38^{a}$ & $89,06^{\mathrm{a}}$ & $92,58^{a b}$ & $99,17^{\mathrm{a}}$ \\
\hline $\begin{array}{l}\mathrm{SD}^{3} \\
L F S^{3}\end{array}$ & $65,24^{\mathrm{c}}$ & $69,06^{\mathrm{b}}$ & $94,76^{\mathrm{ab}}$ & $99,26^{\mathrm{a}}$ \\
\hline $\begin{array}{l}\text { SBIT }^{4} \\
\text { LSTI }^{4}\end{array}$ & $70,06^{\mathrm{b}}$ & $71,74^{b}$ & $84,41^{b}$ & $97,95^{\mathrm{a}}$ \\
\hline $\begin{array}{l}\text { SBITD }^{5} \\
\text { LFLTIS }^{5}\end{array}$ & $52,69^{d}$ & $60,99^{b c}$ & $96,23^{\mathrm{a}}$ & $99,30^{\mathrm{a}}$ \\
\hline $\begin{array}{l}\mathrm{FS}^{6} \\
S M^{6}\end{array}$ & $36,76^{\mathrm{e}}$ & $50,70^{\mathrm{c}}$ & $87,51^{\mathrm{ab}}$ & $98,82^{\circ}$ \\
\hline $\mathrm{CV}$ & \multicolumn{4}{|c|}{$\begin{array}{c}\text { Proteína bruta }(\%)^{1} \\
\text { Crude protein }(\%)^{1}\end{array}$} \\
\hline $\begin{array}{l}\mathrm{S}^{2} \\
S^{2}\end{array}$ & $87,71^{\mathrm{b}}$ & $88,91^{\mathrm{a}}$ & $99,82^{\mathrm{a}}$ & 100,00 \\
\hline $\begin{array}{l}\mathrm{SD}^{3} \\
L F S^{3}\end{array}$ & $88,71^{\mathrm{a}}$ & $76,14^{\mathrm{ab}}$ & $98,80^{\mathrm{a}}$ & 100,00 \\
\hline $\begin{array}{l}\text { SBIT }^{4} \\
\text { LSTI }^{4}\end{array}$ & $53,38^{\mathrm{e}}$ & $60,05^{\mathrm{ab}}$ & $98,99^{\mathrm{a}}$ & 100,00 \\
\hline $\begin{array}{l}\text { SBITD }^{5} \\
L F L T I S^{5}\end{array}$ & $58,32^{\mathrm{c}}$ & $69,08^{\mathrm{ab}}$ & $99,35^{\mathrm{a}}$ & 100,00 \\
\hline $\begin{array}{l}\mathrm{FS}^{6} \\
S M^{6}\end{array}$ & $56,99^{\mathrm{d}}$ & $48,87^{\mathrm{b}}$ & $85,50^{\mathrm{b}}$ & 100,00 \\
\hline $\mathrm{CV}$ & - & 20,5 & 1,8 & - \\
\hline
\end{tabular}

1 Médias acompanhadas de letras diferentes para o mesmo tempo dentro de componentes nutritivos diferem estatisticamente entre si $(P<0,05)$ pelo teste de Tukey (Means followed by different letters for the same time and nutritive component are different by Tukey test $[P<.05])$.

${ }^{2} S$ = grãos de soja comercial moídos ( $S=$ ground soybean).

${ }^{3} \mathrm{SD}=$ grãos de soja comercial moídos e desengordurados (LFS = ground low fat soybean).

4 SBIT = grãos de soja moídos com baixo teor inibidor de tripsina (LSTI = ground low trypsin inhibitor).

${ }^{5}$ SBITD = grãos de soja moídos com baixo teor inibidor de tripsina e desengordurados (LFLTIS = ground low fat and low trypsin inhibitor

${ }^{6} \mathrm{FS}=$ farelo de soja $(\mathrm{SM}=$ soybean meal).
No processo de lavagem, foi observada, também, a formação de espuma branca e água muito turva, fato que pode estar relacionado a perdas de substâncias saponificantes e oleosas. Pode-se considerar, ainda, que os métodos de lavagem usados pelos autores anteriormente citados (lavagem por sifonagem em lavador de pipetas, solução salina e fluido ruminal autoclavado), possivelmente, podem ter levado a menores perdas de partículas sólidas quando comparados no presente trabalho.

A variedade de soja com baixo inibidor tríptico apresentou menor $(\mathrm{P}<0,05)$ degradabilidade da MS e da MO que a variedade de soja convencional, enquanto a PB apresentou tendências similares àquelas observadas para MS e MO durante as seis primeiras horas de incubação.

Pode-se observar na Tabela 2 que o desaparecimento da MO do farelo de soja, no tempo de 48 horas, foi semelhante aos encontrados para os outros alimentos. No entanto, o desaparecimento da MS do farelo de soja foi menor $(\mathrm{P}<0,05)$ que os observados para os demais. Estes valores podem ser atribuídos aos maiores teores de cascas de soja contidos nos farelos de soja encontrados no comércio.

Mir et al. (1984) afirmaram que alimentos incubados in situ com níveis elevados de gordura podem obstruir os poros das bolsas de náilon, causando reduções nas taxas de degradabilidades dos diferentes componentes nutritivos dos alimentos estudados. No entanto, o desaparecimento da PB do grão de soja comercial moído e desengordurado, nos primeiros tempos de incubação (seis horas), foi superior aos demais alimentos estudados, mas não foram observadas diferenças estatísticas para os demais tempos entre os grãos de soja.

Na Tabela 3, podem ser observadas a fração (A), rapidamente degradável no rúmen e a fração (B) insolúvel, potencialmente degradável, taxa de fermentação (kd\%/hora), degradabilidade potencial (DP) e a degradabilidade efetiva (DE) dos alimentos estudados.

Os grãos de soja com alto inibidor tríptico apresentaram fração A da MS, MO e da PB superiores $(\mathrm{P}<0,05)$ aos demais alimentos estudados. Sabe-se que a fração A é composta por duas frações: uma fração solúvel em água e outra composta por partículas sólidas que escapam pelos poros dos sacos de náilon durante o processo de lavagem. Nesse caso, observou-se, durante o trabalho, que os grãos de soja comercial com maior teor de inibidor tríptico tenderam a maior 
Tabela 3 - Frações solúveis (A), insolúvel potencialmente degradável (B), taxa de fermentação (kd\%/h), degradabilidade potencial (DP) e degradabilidade efetiva (DE) da matéria seca, matéria orgânica e proteína bruta

Table 3 - Soluble fraction $(A)$, insoluble fraction potentially degradable (B), fermentation rate (kd\%/h), potential degradability (PD) and effective degradability (ED) of dry matter, organic matter and crude protein

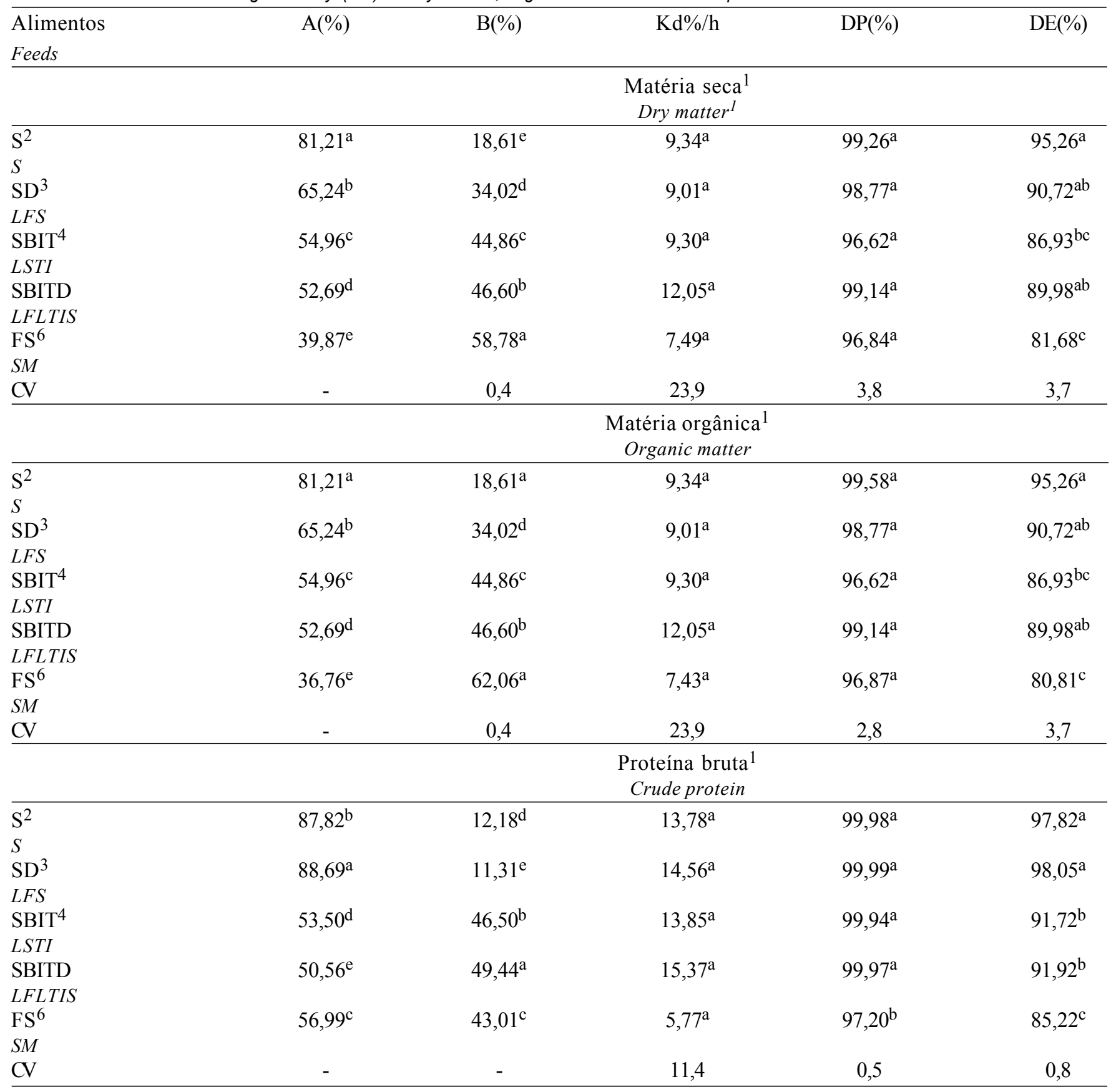

${ }^{1}$ Médias acompanhadas de letras diferentes para o mesmo tempo dentro de componentes nutritivos diferem estatisticamente entre si $(P<0,05)$ pelo teste Tukey.

$2 \mathrm{~S}=$ grãos de soja comercial moídos.

${ }^{3} \mathrm{SD}=$ grãos de soja comercial moídos e desengordurados.

${ }^{4} \mathrm{SBIT}=$ grãos de soja moídos com baixo teor inibidor de tripsina.

5 SBITD = grãos de soja moídos com baixo teor inibidor de tripsina e desengordurados.

${ }^{6} \mathrm{FS}=$ farelo de soja.

${ }^{1}$ Means followed by different letters for the same time and nutritive component are different $(P<.05)$ by Tukey test.

${ }^{2} S=$ ground soybean.

${ }^{3}$ LFS = ground low fat soybean

${ }^{4}$ LSTI = ground low trypsin inhibitor.

${ }^{5}$ LFLTIS = ground low fat and low trypsin inhibitor.

${ }^{6} S M=$ soybean meal. 
pulverulência quando triturados do que os grãos da variedade de soja com menores teores de inibidor tríptico, o que pode ter maximizado a fração $\mathrm{A}$ e, conseqüentimente reduzido os percentuais da fração B. Entretanto, os grãos de soja integrais com baixa inibidor tríptico apresentaram resultados semelhantes àqueles observados por Brisola et al. (1998) com grãos de soja convencional, sem processamento. Por outro lado, os resultados obtidos para PB do grão de soja com baixo teor de inibidor de tripsina foram semelhantes aos encontrados por aqueles autores com soja integral semi-extrusada.

A fração insolúvel, potencialmente degradável, da MS e MO do grão de soja comercial apresentou o menor $(\mathrm{P}<0,05)$ valor em relação aos demais alimentos, o qual pode estar subestimado devido à alta solubilidade já discutida anteriormente. Por outro lado, pode ser observado que o grão de soja moído, quando desengordurado, apresentou o menor valor da fração degradável da PB. Os alimentos apresentaram taxa de fermentação semelhante.

A degradabilidade potencial da MS e da MO apresentou valores entre 96,62 e 99,58\%, mas não diferiu estatisticamente entre os demais alimentos. Por outro lado, observou-se que a DP da PB do farelo de soja $(97,20 \%)$ diferiu estatisticamente $(\mathrm{P}<0,05)$ dos demais alimentos estudados, que não diferiram entre si.

\section{Conclusões}

A variedade de soja com baixos teores de inibidor tríptico apresentou taxas e velocidades de degradação dos componentes nutritivos que permitem o seu uso em substituir total ou parcialmente o grão de soja convencional e o farelo de soja na alimentação dos animais ruminantes.

Os teores de óleo no grão de soja comercial ou no grão de soja com baixo teor de inibidor de tripsina não influíram sobre a degradabilidade efetiva dos componentes nutritivos estudados. A soja integral com ou sem óleo pode substituir o farelo de soja nas rações de ruminantes.

\section{Literatura Citada}

AGRICULTURAL AND FOOD RESEARCH COUNCIL AFRC. Energy and protein requeriments of ruminants. Wallinggford: CAB International, 1993. 159p.

BRISOLA, M.L.; LUCCI, C.S. MELOTTI, L. et al. Degradabilidade ruminal in situ da proteína de grãos de soja extrusados e do farelo de soja. In: REUNIÃO ANUAL DA SOCIEDADE BRASILEIRA DE ZOOTECNIA, 35., 1998, Botucatu, Anais... Botucatu: Sociedade Brasileira de Zootecnia, 1998. p.59-61.
BRODERICK, G.A.; WALLACE, R.J.; ORSKOV, E.R. Control of rate and extent of protein degradation. In: TSUDA, T.; SASAKE, Y.; KAWASHIMA. (Eds.) Physiological aspects of digestion and metabolism in ruminants. San Diego: Academic Press, 1991. 541p.

CASTILHO, A.M.; VALADARES FILHO, S.C.; SILVA, J.F.C. et al. Degradabilidade ruminal da matéria seca e da proteína bruta de alimentos, usando-se a técnica dos sacos de náilon, em vacas gestantes alimentadas com feno (80\%) e concentrado (20\%). Revista Brasileira de Zootecnia, v.22, n.1, p.89-98, 1993.

DESCHAMPS, F.C. Degradabilidade ruminal da matéria seca e da proteína de alguns alimentos utilizáveis na alimentação de ruminantes. Revista Brasileira de Zootecnia, v.23, n.6, p.898-908, 1994.

GREEN, G.M.; LYMAN, R.L. Feedback regulation of pancreatic enzyme secretion as a mechanism for trupsin-induced hypersecretion in the rat. The Proceedings of the Society for Experimental Biology and Medicine, n.140, p.6, 1972.

KROGDAHL, A.; HOLM, H. Inhibition of human and rat pancreatic proteinases by crude and purified soybean proteinase inhibitors. Journal of Nutrition, n.109, p.551-558, 1979.

MIR, Z.; MAcLEOD, G.K.; BUCHANAN-SMITTH, J.G. et al. Methods for protecting soybean and canola proteins from degradation in the rumen. Candian Animal Science, v.64, p.853-865, 1984.

ORSKOV, E.R. Nutrición proteica de los ruminantes. Zaragoza: Acribia, 1988. 178p.

ORSKOV, E.R.; McDONALD, J. The estimation of protein degradability in the rumen from incubation measurements weighted according to rate of passage. Journal of Agriculture, v.92, p.499-503, 1979.

SILVA, D.J. Análise de alimentos (Métodos químicos e biológicos). 2.ed. Viçosa, MG: Universidade Federal de Viçosa, 1990. 165p.

SILVA, L.D.F. Degradabilidade ruminal da casca de soja e fontes protéicas e seus efeitos nas digestões ruminal e intestinal de rações de bovinos. Jaboticabal: Universidade Estadual Paulista, 1999. 110p. Tese (Doutorado em Zootecnia) - Universidade Estadual Paulista, 1999.

SNYDER, H.E.; KWON, T.W. Soybean utilization. New York: 1987. 346p.

TAN-WILSON, A.L.; WILSON, K.A. Revelance of multiple soybean trypsin inhibitors forms to nutritional quality. Advances Experimental Medicine Biology, n.199, p.391411, 1986.

VALADARES FILHO, S.C.; SILVA, J.F.C.; SANT'ANNA, R. et al. Degradabilidade in situ da matéria seca e proteína bruta de vários alimentos em vacas em lactação. Revista Brasileira de Zootecnia, v.19, n.6, p.512-522, 1990.

WEDER, J.K.P. Chemistry of legume protease inhibitors and their use in taxonomy. Quality Plant Foods for Human Nutrition. n.35, p.183-194, 1985. 